\title{
Aspectos patológicos de 155 casos fatais de cães atropelados por veículos automotivos
}

\author{
Pathological aspects of $\mathbf{1 5 5}$ fatal cases of dogs victimized by motor vehicles accidents
}

\author{
Rafael Almeida Fighera ${ }^{\mathrm{I}}$ Marcia Cristina da Silva $^{\mathrm{I}}$ Tatiana Mello de Souza \\ Juliana Sperotto Brum ${ }^{\text {II }}$ Glaucia Denise Kommers ${ }^{\text {III }}$ Dominguita Lühers Graça ${ }^{\text {III }}$ \\ Luiz Francisco Irigoyen ${ }^{\text {III }}$ Claudio Severo Lombardo de Barros ${ }^{\text {III }}$
}

RESUMO

O atropelamento por veículos automotivos contribui significativamente para as estatísticas de morte em cães. Entretanto, há poucos estudos sobre os aspectos patológicos reportados na literatura. Este artigo descreve 155 casos fatais de atropelamento por veículos automotivos em cães. Dos 155 cães atropelados, em 138 (89,0\%) havia lesões que explicavam a morte ou a razão para a eutanásia desses cães. Essas lesões incluíram traumatismo espinhal-medular (43 $[27,7 \%])$, ruptura de órgãos parenquimatosos (40 [25,8\%]), traumatismo cranioencefálico (28 [18,1\%]), ruptura de órgãos ocos (16 [10,3\%]), fratura de costelas com laceração de órgãos parenquimatosos (15 [9,7\%]) e ruptura de diafragma com deslocamento de vísceras abdominais para a cavidade torácica $(10[6,4 \%])$.

Palavras-chave: doenças de cães, trauma, atropelamento, traumatologia, patologia.

\section{ABSTRACT}

Motor vehicle-related trauma significantly contributes to death statistics of dogs. There are however few documented reports on the pathological aspects of such cases. This paper describes 155 fatal cases of dogs victimized by motor vehicle accidents. In 138 (89.0\%) of the 155 dogs hit by motor vehicles there were lesions that could explain the death or reason for these dogs being euthanatized. These lesions included vertebrospinal trauma (43 [27.7\%]), rupture of parenchymal organs (40 [25.8\%]), cranioencephalic trauma (28 [18.1\%]), rupture of hollow organs (16 [10.3\%]), rib fracture with subsequent laceration of parenchymal organs (15 [9.7\%]), and diaphragmatic rupture with displacement of abdominal viscera into the thoracic cavity (10 [6.4\%]).

Key words: diseases of dogs, trauma, motor vehicle accident, traumatology, pathology.

\section{INTRODUÇÃo}

Os traumatismos são considerados uma importante causa de encaminhamento de cães a centros de atendimento veterinário em todo o mundo, contribuindo com aproximadamente $13 \%$ do total de cães atendidos em hospitais norte-americanos (KOLATA, 1980). Em um estudo recente, que pesquisou as causas de morte de cães na área metropolitana de São Paulo, os traumatismos contribuíram com aproximadamente $13 \%$ dos óbitos (BENTUBO et al., 2007). Entre as causas de trauma em cães, o atropelamento por veículos automotivos é tido como a mais prevalente. Nos Estados Unidos, esse tipo de acidente envolvendo cães contribui com aproximadamente $53 \%$ dos casos de traumatismo, uma prevalência maior do que a soma de todas as outras causas de trauma (KOLATA et al., 1974).

Em um estudo clínico que avaliou 600 casos de atropelamento por veículos automotivos (KOLATA \& JOHNSTON, 1975), foi observado que $31 \%$ dos cães tinham apenas lesões superficiais no momento da internação e que, em $69 \%$ dos casos, havia lesões esqueléticas e/ou lesões de tecidos moles. Nesse mesmo estudo, dos cães que morreram ou foram submetidos à eutanásia em decorrência do atropelamento (12,5\%), a maior parte apresentava laceração de órgãos abdominais ou torácicos e traumatismo espinhal-medular.

Embora o atropelamento por veículos automotivos contribua significativamente para as

\footnotetext{
'Programa de Pós-graduação em Medicina Veterinária, área de concentração em Patologia Veterinária, Universidade Federal de Santa Maria (UFSM), 97105-900, Santa Maria, RS, Brasil. E-mail: anemiaveterinaria@yahoo.com.br. *Autor para correspondência. "Curso de Medicina Veterinária, UFSM, Santa Maria, RS, Brasil.

II'Laboratório de Patologia Veterinária, Departamento de Patologia, UFSM, Santa Maria, RS, Brasil.
} 
estatísticas de morte em cães, poucos estudos sobre os aspectos patológicos de casos fatais estão disponíveis na literatura. Portanto, o objetivo deste trabalho é descrever os achados de necropsia observados em 155 cães que foram vítimas de atropelamento por veículos automotivos, no período de janeiro de 1965 a dezembro de 2004. Este estudo faz parte de uma série que vem sendo desenvolvida no Laboratório de Patologia Veterinária (LPV) da Universidade Federal de Santa Maria (UFSM) com a finalidade de documentar as principais doenças que causam a morte ou que levam os cães da nossa região a serem submetidos à eutanásia.

\section{MATERIAL E MÉTODOS}

Foram revisados todos os protocolos de necropsia de cães referentes a um período de 40 anos (janeiro de 1965 a dezembro de 2004) arquivados no LPV da UFSM. Dos protocolos de cães que apresentavam traumatismo decorrente de atropelamento por veículos automotivos, foram coletadas informações referentes à necropsia. Foram incluídos no estudo os cães que morreram espontaneamente, os cães que foram submetidos à eutanásia in extremis e os cães que foram submetidos à eutanásia por apresentarem lesão espinhal que não permitia a locomoção. Não foram incluídos cães que apresentavam lesões passíveis de tratamento clínico e/ou cirúrgico e sofreram eutanásia por conveniência.

As lesões que contribuíram para a morte ou eutanásia foram classificadas dentro de seis grandes grupos previamente definidos: traumatismo cranioencefálico, traumatismo espinhal-medular, ruptura de órgãos parenquimatosos, ruptura de órgãos ocos, fratura de costelas com laceração de órgãos parenquimatosos e ruptura de diafragma com deslocamento de vísceras abdominais para a cavidade torácica. Lesões relacionadas com o acidente, mas que não contribuíram para a morte ou a eutanásia foram consideradas como achados de necropsia.

\section{RESULTADOS E DISCUSSÃO}

Nos arquivos do LPV-UFSM, que compreendem o período entre janeiro de 1965 e dezembro de 2004, foram encontrados 4.844 protocolos de necropsia de cães. Destes, 274 (5,6\%) descreviam casos em que a morte espontânea ou por eutanásia decorreu de algum tipo de traumatismo. Destes 274 casos de trauma, em 155 (56,6\%) a morte espontânea ou a eutanásia resultou de atropelamento por veículos automotivos.
Dos 155 cães atropelados, em 138 (89,0\%) foram encontradas lesões que explicavam a morte ou que contribuíram para que tais cães fossem submetidos à eutanásia. Em 17 (11,0\%) casos, os cães morreram em conseqüência do atropelamento, mas não foram encontradas lesões que explicassem o porquê de sua morte. Dos 138 cães com lesão, em 124 (89,8\%) havia apenas uma lesão diretamente relacionada com a morte e em 14 (10,1\%) havia mais de uma lesão. Considerando os 155 cães atropelados, ocorreram $43(27,7 \%)$ casos de traumatismo espinhal-medular, $40(25,8 \%)$ casos de ruptura de órgãos parenquimatosos, $28(18,1 \%)$ casos de traumatismo cranioencefálico, 16 (10,3\%) casos de ruptura de órgãos ocos, 15 (9,7\%) casos de fratura de costelas com laceração de órgãos parenquimatosos e 10 $(6,4 \%)$ casos de ruptura de diafragma com deslocamento de vísceras abdominais para a cavidade torácica.

Dos 43 casos de traumatismo espinhalmedular, em 33 (76,7\%) foram evidenciadas fraturas de vértebras. Em seis (14,0\%) casos havia luxação vertebral decorrente de ruptura parcial ou total do anel fibroso do disco intervertebral e em quatro $(9,3 \%)$ não foi observada lesão na coluna vertebral. Em todos esses casos havia lesão na medula espinhal, que incluía compressão medular pelo fragmento ósseo deslocado (39 [90,7\%]), laceração (17 [39,5\%]), hemorragia (15 [34,9\%]) e ruptura da dura-máter (4 [9,3\%]). Dos 33 casos em que havia fratura vertebral, 19 (57,6\%) ocorreram na região torácica, 13 (39,4\%) na região lombar e um $(3,0 \%)$ na região cervical. Nos seis casos de luxação vertebral e nos quatro casos em que não havia lesão na coluna vertebral, a lesão medular era localizada na região lombar.

Dos 40 casos em que ocorreu ruptura de órgãos parenquimatosos, em 36 (90,0\%) havia acúmulo de sangue ou coágulos na cavidade abdominal (hemoperitônio) com volume suficiente para explicar a morte do cão por choque hipovolêmico. Em seis $(15,0 \%)$ casos a morte foi atribuída a colapso pulmonar decorrente da associação entre acúmulo de variável quantidade de sangue no interior da cavidade torácica (hemotórax) e perda da pressão negativa intratorácica decorrente da entrada de ar (pneumotórax). Em dois (5,0\%) desses casos de hemotórax e pneumotórax, o hemoperitônio também contribuiu para a morte do cão. Os órgãos afetados nesses casos foram: fígado (25 [62,5\%]), baço (21 [52,5\%]), pulmão (seis [15,0\%]), rim (um [2,5\%]) e pâncreas (um [2,5\%]).

Dos 28 casos de traumatismo cranioencefálico, em 12 (42,8\%) foram evidenciadas fraturas em algum dos ossos do crânio; nos outros $16(57,1 \%)$ havia apenas lesão no encéfalo. As lesões encefálicas observadas incluíam: hemorragia (22 [78,6\%]), ruptura 
da dura-máter (seis [21,4\%]) e laceração decorrente de penetração de esquírolas ósseas na substância encefálica (seis [21,4\%]). Nesses 22 casos em que havia hemorragia, elas foram caracterizadas quanto à localização em: subaracnóidea (10 [45,4\%]), intracerebral (seis [27,3\%]), subdural (quatro [18,2\%]), extradural (dois [9,1\%]) e intraventricular (dois [9,1\%]). Nos 12 casos em que o traumatismo cranioencefálico esteve associado à fratura, os ossos afetados foram: parietal (sete [58,3\%]), frontal (cinco [41,7\%]), temporal (cinco [41,7\%]), esfenóide (dois [16,7\%]) e occipital (um [8,3\%]).

Em todos os 16 casos em que ocorreu ruptura de órgãos ocos havia acúmulo de quantidade variável de líquido abdominal. Esse líquido tinha forte odor amoniacal e variava de amarelo-claro a âmbar (urina) em nove $(56,2 \%)$ casos; tinha odor fétido e variava de amarelo-claro a marrom-escuro (pus) em cinco (31,2\%) casos; era enegrecido e estava misturado ao conteúdo fecal em um (6,2\%) caso; e verde-claro e turvo (bile) em outro (6,2\%). Os órgãos afetados nesses casos foram: bexiga (nove [56,2\%]), intestino delgado (três [18,8\%]), estômago (dois [12,5\%]), intestino grosso (um [6,2\%]), uretra pélvica (um [6,2\%]) e vesícula biliar (um $[6,2 \%]$ ). Dos nove casos de ruptura de bexiga, em três $(33,3 \%)$ havia múltiplas fraturas pélvicas.

Dos 15 casos em que ocorreram fraturas de costelas com subseqüente laceração de órgãos parenquimatosos, em todos havia hemotórax de intensidade variável. Em cinco (33,3\%) desses casos, o volume era suficiente para explicar a morte do cão por choque hipovolêmico, já nos outros 10 (66,7\%) casos havia uma associação entre hemotórax e pneumotórax. Em 13 (86,7\%) desses casos a laceração era pulmonar e em dois (13,3\%) era cardíaca.

Dos 10 casos em que a ruptura de diafragma foi associada à morte do cão, em todos havia deslocamento de órgãos da cavidade abdominal para a cavidade torácica com conseqüente diminuição do espaço para expansão pulmonar. Os órgãos abdominais encontrados no tórax nesses casos foram: fígado (oito [80,0\%]), estômago (cinco [50,0\%]), intestino delgado (cinco [50,0\%]) e baço (três [30,0\%]).

Em todos os cães havia outras lesões decorrentes do atropelamento, mas que não contribuíram diretamente para a morte ou eutanásia. Essas lesões incluíam abrasões e lacerações de pele, tecido subcutâneo, músculos, tendões, vasos e nervos periféricos. Em 50 dos 155 (32,2\%) cães havia também fraturas não-relacionadas com a morte. Essas fraturas estavam distribuídas da seguinte maneira: pelve (20 [12,9\%]), ossos longos (19[12,2\%]) e costelas (11 [7,1\%]). Os 20 casos de fratura de pelve não estiveram relacionados com ruptura de órgãos ocos e os 11 casos de fratura de costela não causaram laceração de órgãos parenquimatosos. Os ossos longos mais freqüentemente acometidos foram: fêmur (15 [78,9\%]), tíbia (cinco [26,3\%]), úmero (cinco [26,3\%]), rádio (quatro [21,0\%]), fíbula (três [15,8\%]) e ulna (dois [10,5\%]).

Entre as diferentes causas de trauma em cães, o atropelamento por veículos automotivos é considerado a segunda com maior índice de letalidade (12,4\%), atrás apenas dos casos de queimadura (KOLATA et al., 1974). A maior parte dos cães observados neste estudo corresponde a casos em que foram encontradas lesões que explicavam a morte ou que eram suficientemente graves para que os proprietários tivessem optado pela eutanásia. Entretanto, em $11,0 \%$ dos casos não se observaram lesões que explicassem a morte dos cães.

Embora casos fatais de atropelamento por veículos automotivos em cães estejam mais freqüentemente relacionados à laceração de órgãos abdominais ou torácicos e à traumatismo espinhalmedular (KOLATA \& JOHNSTON, 1975), algumas hipóteses têm sido propostas para explicar a morte de cães e humanos vítimas desses atropelamentos. Em humanos, os estímulos proporcionados pelo traumatismo resultam em mudanças celulares profundas e a reação geral ao trauma prossegue até níveis sistêmicos (AMARAL et al., 1988), ocasionando, entre outras alterações, respostas metabólicas e cardiovasculares coordenadas pelo hipotálamo (CHIOLERO et al., 1988). Sabe-se que diferentes causas de trauma podem expandir o espaço vascular, o que diminui a pressão venosa, o retorno venoso e o débito cardíaco. Esse fenômeno seqüencial, que acaba causando uma má perfusão tecidual, é denominado de choque distributivo, neurogênico ou vasogênico e ocorre também em casos de anafilaxia e septicemia (HAUPTMAN \& CHAUDRY, 1996). Além disso, tem sido proposto que alterações no ritmo cardíaco podem estar relacionadas à morte de cães envolvidos em acidentes com veículos automotivos (arritmias póstraumáticas) (MACINTIRE \& SNIDER, 1984; SNYDER et al., 2001). Complicações, como hiperglicemia, também têm sido incriminadas na patogênese das alterações metabólicas pós-traumáticas (SYRING et al., 2001). Embora não tenhamos subsídios clínicos para saber porque $11,0 \%$ dos cães deste estudo morreram, choque distributivo, arritmias pós-traumáticas e hiperglicemia são hipóteses que podem ser consideradas.

Na maior parte dos casos avaliados neste estudo havia apenas uma lesão diretamente relacionada com a morte ou a eutanásia do cão, enquanto que em aproximadamente $10,0 \%$ dos casos havia uma 
combinação entre essas lesões. Este resultado demonstra que, nos casos fatais de atropelamento por veículos automotivos, é cerca de nove vezes mais freqüente se atribuir a morte do cão a apenas uma lesão.

Dentre as lesões que causaram morte ou levaram os cães a serem submetidos à eutanásia, o traumatismo espinhal-medular e o traumatismo cranioencefálico foram muito prevalentes. Segundo alguns autores, o traumatismo espinhal-medular é a causa mais importante de eutanásia em cães vítimas de atropelamento por veículos automotivos, já traumatismo cranioencefálico não é considerado uma causa comum (KOLATA \& JOHNSTON, 1975). Esses mesmos autores explicam que, na maior parte dos casos em que ocorre traumatismo cranioencefálico, os cães morrem rapidamente, o que faz com que não sejam encaminhados aos serviços de emergência. Assim, como o presente estudo foi realizado a partir de protocolos de necropsia e não a partir de protocolos de atendimento clínico, é de se esperar que haja essa diferença.

A alta prevalência do traumatismo espinhalmedular provavelmente se deve ao local do impacto do veículo no corpo dos cães. Segundo a literatura, a maioria dos cães atropelados por veículos automotivos é atingida lateralmente (KOLATA \& JOHNSTON, 1975). Além disso, a altura média dos pára-choques da maior parte dos veículos é semelhante à altura média da coluna vertebral de cães de porte médio e grande. Assim, acreditamos que, na maior parte dos casos, os cães possam ter sido atingidos ao longo do seu esqueleto axial, o que ocasionou uma alta prevalência de traumatismo espinhal-medular.

$\mathrm{Na}$ maioria dos cães que sofreram traumatismo espinhal-medular, foram evidenciadas fraturas de vértebras e essas fraturas foram muito mais prevalentes nas regiões torácica e lombar do que na região cervical. Dessa forma, observou-se que é 19 e 13 vezes mais freqüente um cão vítima de atropelamento por veículos automotivos morrer ou sofrer eutanásia em decorrência de traumatismo espinhal-medular ocasionado por fratura das vértebras torácica ou lombares, respectivamente, do que por fraturas de vértebras cervicais. Estes resultados são semelhantes aos observados por outros autores (HAWTHORNE et al., 1999), como em um grande estudo sobre fratura de coluna vertebral em cães e gatos (SELCER et al., 1991), no qual as regiões torácica e lombar foram, em média, sete vezes mais afetadas do que a região cervical. Em outro estudo, que avaliou 600 casos de atropelamento por veículos automotivos em cães (KOLATA \& JOHNSTON, 1975), observou-se que lesões de medula espinhal lombar e torácica decorrentes de fraturas foram aproximadamente 23 e sete vezes, respectivamente, mais freqüentes do que lesões de medula espinhal cervical. Esses autores atribuem essa diferença ao pequeno tamanho e à grande flexibilidade da região cervical.

Nos casos em que o traumatismo espinhalmedular não esteve associado à fratura, a lesão medular ocorreu sempre em algum ponto da coluna lombar. Acreditamos que isso possa resultar da maior mobilidade da coluna vertebral nessa região, já que, para alguns autores (BRAUND et al., 1990), a região torácica é a porção mais estável da coluna vertebral.

Diferentemente dos casos de traumatismo espinhal-medular, a maior parte dos cães que desenvolveram traumatismo cranioencefálico não apresentavam fratura dos ossos do crânio, entretanto, a grande maioria deles demonstrava graus variáveis de hemorragia, resultados relativamente semelhantes aos observados em outro estudo (DEWEY et al., 1993).

Em humanos que são vítimas de traumatismo cranioencefálico, os tipos mais freqüentes de hemorragia são os hematomas extradurais e subdurais (CROOKS, 1991). Em medicina veterinária, tais hemorragias são incomuns a raras (SUMMERS et al., 1995), com exceção dos primatas, que desenvolvem um padrão semelhante ao observado em humanos (ADAMS et al., 1983). Em nenhum dos cães que desenvolveram hemorragia como parte do quadro de traumatismo cranioencefálico aqui descrito havia volume sangüíneo suficiente para ser considerado como hematoma. À semelhança do que tem sido descrito na literatura (SUMMERS et al., 1995), na maior parte dos casos em que havia hemorragia, ela era subaracnóidea. Entretanto, alguns autores (DEWEY et al., 1993) afirmam que hemorragias subdurais podem ser mais freqüentes do que hemorragias subaracnóideas em animais.

Conforme outros autores (SHELL \& DYER, 1996), hemorragias intraparenquimatosas são mais comuns do que hemorragias subaracnóideas e subdurais em cães e gatos. Neste estudo, casos de hemorragia intracerebral e intraventricular foram bem menos comuns e estiveram sempre associados à laceração decorrente de penetração de esquírolas ósseas na substância encefálica. Talvez esses autores (SHELL \& DYER, 1996) considerem hemorragias intraparenquimatosas mais comuns do que hemorragias subaracnóideas por incluírem nesse grupo casos de contusão encefálica. Entretanto, embora contusão encefálica se caracterize por hemorragia na substância cinzenta, essa lesão não é considerada na distribuição das hemorragias pela maior parte dos autores. 
Em nenhum dos casos de traumatismo cranioencefálico aqui descritos se fez menção à contusão encefálica. O termo contusão designa lesão direta ao parênquima cerebral por meio da transmissão de energia cinética para o encéfalo, à semelhança do que é descrito para os tecidos moles (FREYTAG \& LINDENBERG, 1957). Macroscopicamente, contusões são vistas à necropsia como áreas de hemorragia focal ou eventualmente confluentes na superfície cortical, principalmente nas cúpulas dos giros (PITTELLA \& GUSMÃO, 1999). Ao corte, ocorrem como áreas cuneiformes com base larga sobre a superfície cortical e centradas no ponto de impacto, por vezes estendendo-se até a substância branca subcortical (LINDENBERG \& FREYTAG, 1960). Histologicamente, os estágios iniciais da contusão são vistos como edema e hemorragia pericapilar. Passadas algumas horas da injúria, observa-se hemorragia que se estende do córtex até a substância branca e até o espaço subaracnóideo (FREYTAG \& LINDENBERG, 1957; LINDENBERG \& FREYTAG, 1960). Com base no fato de que contusões freqüentemente são vistas em um estágio em que já há evolução da hemorragia pericapilar para hemorragia subaracnóidea, é possível que muitas das hemorragias observadas em cães deste estudo e classificadas como subaracnóideas sejam na verdade áreas de contusão. No entanto, como em nenhum dos protocolos a hemorragia subaracnóidea foi descrita em associação com hemorragia cortical, não podemos determinar se houve ou não contusão nesses casos.

À semelhança do que é visto por outros autores (KOLATA \& JOHNSTON, 1975; BOYSEN et al. 2004), uma causa importante de morte dos cães atropelados por veículos automotivos deste estudo foi a ruptura de órgãos parenquimatosos. Na grande maioria desses casos havia hemoperitônio com volume suficiente para explicar a morte do cão por choque hipovolêmico. Em todos os casos em que o hemoperitônio causou a morte dos cães houve ruptura de fígado e/ou baço. Em uma parcela menor de casos a morte foi atribuída a colapso pulmonar decorrente de ruptura de pulmão com subseqüente hemotórax e pneumotórax. A soma dos casos de colapso pulmonar decorrentes de ruptura de pulmão com os casos em que ocorreram fraturas de costelas com subseqüente perfuração de pulmão indica que $12,2 \%$ dos cães deste estudo morreram por pneumotórax e/ou hemotórax em decorrência de algum tipo de laceração pulmonar, uma prevalência muito semelhante à observada em um grande estudo (KOLATA \& JOHNSTON, 1975), mas três vezes menor do que aquela encontrada em outro (SPACKMAN et al., 1984). Além disso, se a essa prevalência forem acrescidos os casos em que a ruptura de diafragma esteve associada a deslocamento de órgãos da cavidade abdominal para a cavidade torácica com conseqüente diminuição do espaço para expansão pulmonar, o índice de casos em que a insuficiência respiratória contribuiu na morte dos cães será de 18,7\%.

\section{CONCLUSÃO}

Embora casos fatais de atropelamento por veículos automotivos sejam freqüentemente vistos na rotina da clínica e da patologia veterinária, poucos são os estudos disponíveis sobre a causa da morte ou a razão da eutanásia de cães envolvidos nesses acidentes. No presente estudo pôde-se observar que o traumatismo espinhal-medular decorrente de fratura vertebral, o traumatismo cranioencefálico sem fratura, o hemoperitônio ocasionado por ruptura de fígado e/ ou baço e o colapso pulmonar decorrente de ruptura de pulmão com subseqüente hemotórax e pneumotórax são as principais situações clinicopatológicas que culminam na morte de cães envolvidos neste tipo de agravo. Os resultados aqui apresentados podem servir para alertar os clínicos sobre quais lesões potencialmente fatais podem ser esperadas quando é atendido um cão atropelado por veículo automotivo em clínicas e hospitais veterinários.

\section{APRESENTAÇÃO}

Este trabalho é parte da tese de doutorado do primeiro autor.

\section{REFERÊNCIAS}

ADAMS, J.H. et al. Head injury in man and experimental animals: neuropathology. Acta Neurochirurgica, v.32 (Suppl), p.15-30, 1983.

AMARAL, J.F. et al. The temporal characteristics of the metabolic and endocrine response to injury. Journal of Trauma, v.28, n.9, p.1335-1352, 1988.

BENTUBO, H.D.L. et al. Expectativa de vida e causas de morte em cães na área metropolitana de São Paulo (Brasil). Ciência Rural, v.37, n.4, p.1021-1026, 2007.

BOYSEN, S.R. et al. Evaluation of a focused assessment with sonography for trauma protocol to detect free abdominal fluid in dogs involved in motor vehicle accidents. Journal of the American Veterinary Medical Association, v.225, n.8, p.1198-1204, 2004.

BRAUND, K.G. et al. The etiology, pathology and pathophysiology of acute spinal cord trauma. Veterinary Medicine, v.85, n.7, p.684-691, 1990.

CHIOLERO, R. et al. Plasma pituitary hormone levels in severe trauma with and without head injury. Journal of Trauma, v.28, n.9, p.1368-1374, 1988.

Ciência Rural, v.38, n.5, ago, 2008. 
CROOKS, D.A. Pathogenesis and biomechanics of traumatic intracranial haemorrhages. Virchows Archiv A Pathological Anatomy and Histopathology, v.418, n.6, p.479-483, 1991.

DEWEY, C.W. et al. Acute traumatic intracranial haemorrhage in dogs and cats. A retrospective evaluation of 23 cases. Veterinary Compendium of Orthopedic and Traumatology, v.6, n.3, p.153-159, 1993.

FREYTAG, E.; LINDENBERG, R. Morphology of cortical contusions. AMA Archives of Pathology, v.63, n.1, p.23-42, 1957.

HAUPTMAN, J.; CHAUDRY, I.H. Choque. In: BOJRAB, M.J. Mecanismos da moléstia na cirurgia dos pequenos animais. 2.ed. São Paulo: Manole, 1996. Cap.4, p.21-25.

HAWTHORNE, J.C. et al. Cervical vertebral fractures in 56 dogs: A retrospective study. Journal of the American Animal Hospital Association, v.35, n.2, p.135-146, 1999.

KOLATA, R.J. et al. Patterns of trauma in urban dogs and cats: a study of 1,000 cases. Journal of the American Veterinary Medical Association, v.164, n.5, p.499-502, 1974.

KOLATA, R.J.; JONHSTON, D.E. Motor vehicle accidents in urban dogs: a study of 600 cases. Journal of the American Veterinary Medical Association, v.167, n.10, p.938-941, 1975.

KOLATA, R.J. Trauma in dogs and cats: an overview. Veterinary Clinical of North American: Small Animal Practice, v.10, n.3, p.515-522, 1980.

LINDENBERG, R.; FREYTAG, E. The mechanism of cerebral contusions: a pathologic-anatomic study. Archives of Pathology, v.69, s/n, p.440-469, 1960.
MACINTIRE, D.K.; SNIDER, T.G. Cardiac arrhythmias associated with multiple trauma in dogs. Journal of the American Veterinary Medical Association, v.184, n.5, p.541-545, 1984.

PITTELLA, J.E.H.; GUSMÃO, S.S. Contusão cerebral em vítimas fatais de acidente de trânsito. Arquivos de Neuropsiquiatria, v.57, n.3, p.848-852, 1999.

SELCER, R.R. et al. Management of vertebral column fractures in dogs and cats: 211 cases (1977-1985). Journal of the American Veterinary Medical Association, v.198, n.11, p.1965-1968, 1991.

SHELL, L.; DYER, K.R. Lesões ao cérebro. In: BOJRAB, M.J. Mecanismos da moléstia na cirurgia dos pequenos animais. 2.ed. São Paulo: Manole, 1996. Cap.151, p.13061310 .

SNYDER, P.S. et al. Electrocardiographic findings in dogs with motor vehicle-related trauma. Journal of American Animal Hospital Association, v.37, n.1, p.55-63, 2001.

SPACKMAN, C.J. et al. Thoracic wall and pulmonary trauma in dogs sustaining fractures as a result of motor vehicle accidents. Journal of the American Veterinary Medical Association, v.185, n.9, p.975-977, 1984.

SUMMERS, B.A. et al. Injuries to the central nervous system. In: _. Veterinary neuropathology. St. Louis: Mosby, 1995. Cap.4, p.189-207.

SYRING, R.S. et al. Hyperglycemia in dogs and cats with head trauma: 122 cases (1997-1999). Journal of the American Veterinary Medical Association, v.218, n.7, p.1124-1129, 2001 